\title{
Vaccination with dendritic cells loaded with HIV-1 lipopeptides elicits broad T cell immunity and control of viral load in HIV infected patients
}

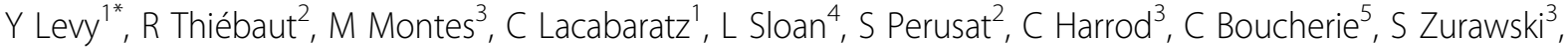 \\ L Richert ${ }^{2}$, G Chêne $^{2}$, J Banchereau ${ }^{3}$, K Palucka ${ }^{3}$
}

From AIDS Vaccine 2012

Boston, MA, USA. 9-12 September 2012

\section{Background}

The DALIA trial tested the hypothesis that immunization with HIV peptide loaded Dendritic Cells (DC) may improve HIV immune responses and help to contain viral replication.

\section{Methods}

19 pts with CD $>500$ cells $/ \mathrm{m} 3$ and HIV RNA $<50 \mathrm{cp} / \mathrm{ml}$ under HAART received at W0, 4, 8 and 12 ex-vivo generated IFN- $\alpha$ DC loaded with HIV-1 lipopeptides. Analytical treatment interruption (ATI) was conducted from W24. HAART resumption regardless of the reason and CD4 $<350$ cells $/ \mathrm{mm} 3$ (or $<25 \%$ ) were considered as end points. HIV-specific immunity was evaluated at baseline, W16, and W48 using: i) ex vivo IFN- $\gamma$ ELISPOT; ii) intra cellular staining; iii) multiplex analysis. PBMCs were stimulated with HIV peptide pools. Student t-test and Wilcoxon signed-rank tests were used with estimation of the False Discovery Rates (FDR) for controlling test multiplicity.

\section{Results}

Vaccine regimen was well tolerated. Following ATI, all pts experienced a viral rebound in 14 days in median (IQR 827). Median highest observed VL (peak) was 5 (4.28-5.23) $\log 10 \mathrm{cp} / \mathrm{ml}$. Three patients resumed HAART and eight had CD4 <350 cells/mm3. Median (IQR) SFU/106 PBMC rose from 186 (140-670) at baseline to 761 (470-1154) and 1878 (1102-4443) at W16 and 48, respectively. At the same time points the breadth of the response (nb of peptide pools) increased from $1(1-3)$ to $4(2-5)(\mathrm{P}=.009)$ and $6(3-7)(\mathrm{P}=.008)$. \% of polyfunctional $\mathrm{CD} 4+(>2$ cytokines among: IFN- $\gamma$, TNF- $\alpha$, IL-2) increased from $0.026 \%(\mathrm{w}-4)$ to $0.32 \%$ (w16) $(\mathrm{P}=.002)$. Respective $\%$ of $\mathrm{CD} 8+$ were $0.26 \%$ and $0.35 \%(\mathrm{P}=.005)$. Production of IL-2, IFN-g, IL-21, IL-13, IL-17 increased significantly at W16 $(\mathrm{FDR}<.05)$. An inverse correlation was found between the peak of VL and \% of polyfunctional CD4+ $(\mathrm{r}=-0.63$, $\mathrm{FDR}=.007)$, production of IL-2 ( $\mathrm{r}=-0.67, \mathrm{FDR}=.006)$, IFN-g $(\mathrm{r}=-0.58, \mathrm{FDR}=.01), \mathrm{IL}-21(\mathrm{r}=-0.66, \mathrm{FDR}=0.006)$ and IL-13 $(\mathrm{r}=-0.78, \mathrm{FDR}=.001)$.

\section{Conclusion}

DC vaccination elicited polyfunctional HIV-specific responses associated with a reduced peak viral load following ATI.

\section{Author details}

'INSERM U955-Université Paris Est, Créteil, France. ${ }^{2}$ INSERM, U897, France Univ Bordeaux Segalen, Bordeaux, France. ${ }^{3}$ INSERM U899-Baylor Institute for Immunology Research, Dallas, TX, USA. ${ }^{4}$ Baylor Institute for Immunology Research, Dallas, TX, USA. IINSERM U897, Bordeaux, France.

Published: 13 September 2012

\section{doi:10.1186/1742-4690-9-S2-P328}

Cite this article as: Levy et al: Vaccination with dendritic cells loaded with HIV-1 lipopeptides elicits broad T cell immunity and control of viral load in HIV infected patients. Retrovirology 2012 9(Suppl 2):P328. 